\title{
Entre a racionalidade produtiva e a conservação do ambiente: a produção oleira do município de Iranduba e suas consequências ambientais
}

\author{
Hamida Assunção Pinheiro* \\ Antonio Carlos Witkoski*
}

\section{Resumo:}

No Estado do Amazonas, o município de Iranduba é conhecido como um dos principais polos de produção de tijolos. A indústria cerâmico-oleira se destaca na economia do município como uma das principais atividades econômicas. $\mathrm{O}$ objetivo do trabalho é problematizar alguns dos principais danos ambientais provenientes da atividade oleira no município de Iranduba. A investigação é de cunho qualitativo e se utiliza da observação, dos registros fotográficos e do diário de campo como instrumentos de coleta de dados. A pesquisa tem revelado que a indústria oleira ocasiona várias consequências ambientais, como por exemplo, a abertura de gigantescas cavas no solo para retirada de argila, o corte intenso de madeira para alimentação dos fornos, a excessiva emissão de fumaça proveniente da queima dos artefatos cerâmicos.

Palavras-chaves: Indústria cerâmico-oleira; Racionalidade Produtiva; Racionalidade Ambiental

\begin{abstract}
:
In Amazonas State, the municipality of Iranduba is known as one of the main of the bricks productions. The pottery-ceramic industry stands out in the city's economy as one of the main economic activities. The objective of this text is to discuss some of the major environmental damage from pottery-ceramic industry in the municipality of Iranduba. The research is qualitative and using uses as collection instruments, the observation, the photographic records and annotations in the field notebook. The Research has revealed that the pottery-ceramic industry causes several environmental consequences, as for example, the opening holes in

* Docente do Departamento de Serviço Social da Universidade Federal do Amazonas e Doutoranda em Ciências do Ambiente e Sustentabilidade na Amazônia pela Universidade Federal do Amazonas. E-mail: hamida.assuncao@gmail.com.

* Doutor em Sociologia, Docente do Departamento de Ciências Sociais e professor do Programa de Pós-Graduação em Ciências do Ambiente e Sustentabilidade na Amazônia da UFAM (professor colaborador), no Programa de Pós-Graduação em Sociologia (professor permanente) e no Programa de Pós-Graduação Sociedade e Cultura na Amazônia (professor permanente). E-mail: acwitkoski@uol.com.br.
\end{abstract}

Latitude, vol. 5, n², pp.49-73, 2011

DOI: https://doi.org/10.28998/2179-5428.20110204 


\section{Entre a racionalidade produtiva e a conservação do ambiente: a produção oleira do município de Iranduba e suas consequências ambientais}

the ground for removal of clay, excessive smoke from burning process of ceramic artifacts.

Keywords: Pottery-ceramic Industry; Productive Rationality; Environmental Rationality

\section{INTRODUÇÃO}

A atividade oleira é proveniente da indústria cerâmica, a qual se caracteriza pela habilidade com a modelagem de artefatos compostos de $\operatorname{argila}^{1} \mathrm{e}$ enrijecidos após a secagem e a queima em fornos com capacidade para altas temperaturas. As técnicas de modelar, secar e queimar a argila formam a base da indústria cerâmica, a qual é responsável pela fabricação de uma diversidade de produtos, que vão desde objetos artísticos e utensílios domésticos a artigos voltados para a construção civil, como os tijolos, telhas, blocos cerâmicos etc.

A produção de cerâmica voltada para a construção civil nasceu na Antiguidade (4.000 a 476 a.C.). Antes disso semelhante técnica já era usada para a fabricação de vasilhas, tigelas, jarros, urnas e outros recipientes úteis para a vida cotidiana dos povos Pré-históricos. Na Pré-História, os artefatos cerâmicos serviam para o armazenamento de grãos, sementes, raízes e água, para o sepultamento dos mortos, como tapa sexo, estatuetas etc. O trabalho de fabricação de objetos cerâmicos permeia a história da humanidade.

$\mathrm{Na}$ atualidade, a indústria cerâmico-oleira constitui-se como um importante ramo socioeconômico, responsável pela geração de receitas e por muitos postos de trabalho. Mas é um setor produtivo de forte impacto ambiental, os quais podem até mesmo ser irreversíveis, na medida em que esta indústria faz uso de recurso natural não renovável, a argila. No caso da madeira ,mesmo sendo um recurso renovável, a ação predatória é preocupante, pois a renovação não acompanha o ritmo de produção.

O presente artigo é fruto de dados e reflexões preliminares que estão sendo realizadas para um trabalho de tese vinculado ao programa de Pós-Graduação em Ciências do Ambiente e Sustentabilidade na Amazônia-PPGCASA da Universidade Federal do Amazonas. Estão sendo realizadas entrevistas semiestruturadas junto aos trabalhadores, ex-trabalhadores, líderes sindicais e

\footnotetext{
${ }^{1}$ A argila é um "material constituído em grande parte de minerais argilosos (argilomineral), isto é, óxidos livres e minerais primários. [É a] fração do solo com diâmetro equivalente menor que $0,002 \mathrm{~mm}[\ldots]$. O termo regional para a argila é o barro. Na linguagem popular, o termo barro é, na maioria das vezes, empregado para caracterizar as argilas vermelhas" (LIMA-e-SILVA, GUERRA e MOUSINHO, 1999, pp. 19 e 28).
} 
Hamida Assunção Pinheiro

Antonio Carlos Witkoski

diretores da Associação dos Ceramistas do Estado do Amazonas - ACERAM. Além disso, tem sido realizadas visitas em várias indústrias cerâmico-oleiras para a observação das particularidades do trabalho oleiro e de suas consequências para o ambiente. Soma-se a isto as anotações no diário de campo e os registros fotográficos que têm sido usados como instrumentos de coleta de dados.

Neste texto, a intenção é problematizar as relações contraditórias entre a racionalidade produtiva, que norteia as indústrias, e a conservação do ambiente, tomando como referência os danos ambientais da indústria cerâmico-oleira do Estado do Amazonas, mais especificamente das indústrias que se localizam no município de Iranduba.

\section{RACIONALIDADE PRODUTIVA X CONSERVAÇÃO DO AMBIENTE}

A acumulação de capital no sistema capitalista de produção se sustenta na exploração (e na super exploração) da força de trabalho e no uso (e até mesmo no abuso) dos recursos naturais. A acumulação é orientada pela busca incessante de lucro proveniente da venda dos produtos no mercado consumidor. A acumulação só acontece por que há produção e consumo de mercadorias, de bens e de serviços. A classe do capital explora a força de trabalho ao máximo e toma os recursos disponíveis na natureza com objetivo de produzir cada vez mais mercadorias para a comercialização É esta lógica que sustenta a desigualdade entre as classes sociais antagônica: classe trabalhadora e classe do capital.

Esta dinâmica gera o que o autor denomina de irracionalidade produtiva. A irracionalidade produtiva ocasiona, a médio e longo prazo, a degradação do potencial produtivo do ambiente em nome da maximização dos ganhos privados (LEFF, 2009).

Desde o século XIX, tem vindo à tona numerosos desastres ambientais decorrentes de processos industriais, que afetam duramente a vida no planeta, entre os quais vale mencionar: a chuva ácida, o efeito estufa, a erosão de solo, o aumento de temperatura etc. A racionalidade econômica, norteada pelas forças produtivas no capitalismo, tem resultado nestes e em muitos outros problemas ambientais.

A racionalidade produtiva ou econômica, de cunho produtivista exacerbado, defronta-se com a racionalidade ambiental, na medida em que apregoa um ritmo acelerado para a o uso dos recursos naturais, para a produção e para o consumo de mercadorias. Já a racionalidade ambiental privilegia uma perspectiva mais sustentável de acesso e uso dos recursos naturais, a qual deve respeitar o tempo de recuperação da natureza, evitar o desperdício e o esgotamento em curto prazo de tempo e operacionalizar formas de recuperação de ambientes degradados. Em síntese, a racionalidade ambiental pauta-se no uso racional, inteligente, eficaz e eficiente dos recursos naturais. A racionalidade 


\section{Entre a racionalidade produtiva e a conservação do ambiente: a produção oleira do município de Iranduba e suas consequências ambientais}

ambiental se fundamenta numa ética que planeja racionalmente o uso dos recursos naturais em nome de uma solidariedade sincrônica e diacrônica, ou seja, da geração presente com ela mesma e da geração presente com as futuras gerações (LEFF, 2006).

De acordo com Leff (2006) a racionalidade produtiva é antagônica à racionalidade ambiental. Esta última entra em choque com os interesses do grande capital, tendo em vista que defende um novo conceito de democracia fundamentado na apropriação coletiva e não privada dos recursos naturais, bem como na equidade social. A racionalidade ambiental rompe com a soberania do cidadão consumidor instalada pela globalização econômica moderna e busca uma soberania dos povos indiscriminadamente. Numa ótica mais ecológica, a racionalidade econômica é considerada irracionalidade, justamente por ignorar ou pouco considerar as consequências ambientais.

Leff (2006) explica que a crise ambiental foi a grande desmancha prazeres do desenvolvimentismo, além de ter explicitado as falhas do modelo civilizatório posto em prática amplamente na modernidade. Na atualidade, a humanidade (ou pelo menos uma parte dela) tem sido obrigada a repensar suas práticas ecológicas e econômicas, sob pena de ter sua qualidade de vida deteriorada num processo de autodestruição. A degradação ecológica é o marco de uma crise da civilização fundada na racionalidade econômica capitalista, por isso é preciso pensar criticamente a ordem do mundo atual, para se construir uma outra racionalidade descolada de interesses puramente econômicos e mais centrada no equilíbrio entre as esferas econômica, ecológica e social.

No entanto, o autor alerta que a ética ambiental é incapaz de conter sozinha a destruição da natureza e a força voraz da classe do capital pela acumulação. A constituição de uma racionalidade ambiental é um processo político e social que requer uma delicada negociação entre interesses opostos, novas formas de organização produtiva, inovações tecnológicas e metodológicas etc. A formação de outra racionalidade produtiva mais coerente com os princípios da sustentabilidade é um processo longo e de difícil construção, visto que depende da percepção das injustiças do modelo atual, do emprenho em prol da emancipação dos indivíduos e também da reorientação moral do desejo de consumo individual e coletivo. O processo envolve não só mudança de pensamento, mas também um conjunto de transformações sociais (LEFF, 2006).

Contudo, a realidade concreta é cheia de contradições. No capitalismo contemporâneo, a ideologia neoliberal marca presença e opera de modo a desenvolver formas mais sutis para continuar explorando intensamente os recursos naturais e também degradando o ambiente de forma direta e indireta. A produção e o consumo se dão em uma cadência bastante acelerada que ultrapassa os limites de sustentabilidade do planeta. Mesmo em meio ao esgotamento e/ou à ameaça de escassez de diversos recursos naturais, a ideologia neoliberal 
Hamida Assunção Pinheiro

Antonio Carlos Witkoski

reinterpreta a concepção de desenvolvimento sustentável e a emprega como forma de legitimar a degradação ambiental como necessária para o crescimento econômico da sociedade (LEFF, 2008).

Prova de tais acontecimentos podem ser identificadas nas inúmeras empresas que se mostram adeptas e defensoras das causas ambientais, mas continuam fazendo uso de processos produtivos extremamente agressivos ao ambiente, como por exemplo: o descarte incorreto de materiais contaminados, a emissão de gases poluentes, derramamento de óleos etc. Tem se tornado muito comum em diferentes setores empresariais, uma espécie de investimento em um marketing ecológico, descolado do investimento em máquinas, equipamentos, produtos e processos menos poluentes e destruidores do ambiente. A preocupação das empresas está mais centrada na melhoria da imagem social do que na proteção ambiental de fato (CESAR, 2008).

Cesar (2008) realizou pesquisa aprofundada em 46 grandes e médias empresas espalhadas por todo Brasil e identificou que o discurso empresarial nem sempre condiz com práticas democráticas internas (com funcionários) e externas (consumidores/sociedade). As ações de responsabilidade socioambiental das empresas estão mais preocupada em divulgar que atuam respeitando a sustentabilidade, do que verificar se os resultados têm contribuído para a proteção do ambiente e para a melhorias das condições de vida dos cidadãos. Esta tendência observada pela autora tem impactos preocupantes.

O marketing ecológico ou verde, como também é chamado, pode até contribuir para a melhoria da imagem da empresa, mas a sociedade como um todo, mesmo sem saber, paga pelas artimanhas empresariais de manter tecnologias degradantes. A empresa até consegue ludibriar o consumidor, mas jamais fará o mesmo com o ambiente. O ambiente é formado por muitos ecossistemas interligados e interdependentes, os quais reagem com violência às ações predatórias dos homens.

Quando se trata da exploração dos recursos naturais com finalidade comercial, as consequências ambientais podem assumir proporções desastrosas. A amplitude destes impactos varia de acordo com a aplicação ou não de instrumentos que promovam o uso racional dos recursos naturais e de ferramentas que reduzam os danos. A legislação ambiental assume posição de grande relevância nesse cenário, haja vista que o Brasil é reconhecido internacionalmente pela qualidade de seus instrumentos normativos voltados para a conservação e preservação do ambiente.

Apesar da existência de legislação ambiental para vários problemas ambientais provenientes da indústria cerâmico-oleira, os mesmos se colocam como um desafio para a sociedade. A atividade cerâmico-oleira produz impactos socioambientais significativos, uma vez que emprega recursos naturais renováveis e não renováveis para a fabricação dos produtos cerâmicos, como é o caso da 
Entre a racionalidade produtiva e a conservação do ambiente: a produção oleira do município de Iranduba e suas consequências ambientais

madeira (em forma de lenha) e da argila respectivamente.

É preciso esclarecer que a indústria cerâmico-oleira, apesar de se caracterizar pelo uso de um minério não renovável e pelo uso da madeira, pode e deve ser pensada a partir de processos menos devastadores. São possíveis e necessárias medidas que evitem o esgotamento dos recursos e possibilitem a eliminação ou, pelo menos, a diminuição dos danos ambientais.

A indústria cerâmico-oleira é responsável por uma boa quantidade de danos ambientais que se tornam evidentes pela excessiva emissão de fumaça expelida pelas chaminés dos fornos, pela extração de argila em áreas próximas às margens dos rios, pelo descarte de restos de material cerâmico a céu aberto, pelo desflorestamento de grandes áreas etc. Estes danos serão mostrados e discutidos na seção seguinte com base na realidade das indústrias em Iranduba.

\section{A PRODUÇÃO OLEIRA E SUAS CONSEQUÊNCIAS AMBIENTAIS EM IRANDUBA}

O município de Iranduba foi criado oficialmente em 1981, no entanto, há registros históricos que indicam ocupações de nativos indígenas, mais especificamente dos índios Mura, desde o século XVIII. As origens históricas de Iranduba estão vinculadas às ocupações seculares dos povos indígenas e ao processo de colonização portuguesa. As correspondências trocadas entre agentes da Coroa Portuguesa e seus dirigentes, bem como as escavações arqueológicas mais recentes, evidenciam a presença de índios na região onde se localiza o município (CHAVES, 1990).

O município de Iranduba está situado no Estado do Amazonas e possui uma área de $2.214 \mathrm{Km}^{2}$ e uma população de 40.781 habitantes, conforme dados do último censo realizado em 2010 pelo Instituto Brasileiro de Geografia e Estatística IBGE.

A indústria cerâmico-oleira no Amazonas está bastante concentrada no município de Iranduba, conforme informações da ACERAM, existem 28 indústrias em todo o Estado, sendo que, 14 estão em Iranduba, 9 em Manacapuru, 1 em Novo Airão, 1 em Tefé, 1 em Itacoatiara, 1 em tabatinga e 1 em Parintins. O Polo cerâmico-oleiro do Estado é formado pelos municípios de Iranduba e Manacapuru, mas neste artigo o objetivo é focar somente em Iranduba, pois este agrupa a maior parte das indústrias.

A produção das indústrias cerâmico-oleiras do Estado é consumida internamente, pois não há escoamento para outros estados, e nenhuma delas conta com incentivos fiscais da Zona Franca de Manaus - ZFM por estarem fora da área de abrangência. A área de abrangência da ZFM para projetos industriais e agropecuários, conforme estabelece o art. $2^{\mathrm{o}}$ do Decreto-Lei $\mathrm{n}^{\mathrm{o}}$ 288/67, é constituída por uma contínua superfície de dez mil quilômetros quadrados, incluindo a cidade de Manaus e seus arredores, na margem esquerda dos rios Negro e Amazonas. 
Hamida Assunção Pinheiro

Antonio Carlos Witkoski

Esta área é bem menor que a Região Metropolitana de Manaus - RMM, que foi criada em 30 de maio de 2007, através da Lei Complementar Estadual no. 52, compreendendo os municípios de Iranduba, Manacapuru, Novo Airão, Careiro da Várzea, Presidente Figueiredo, Rio Preto da Eva e Itacoatiara. Sendo assim, as indústrias cerâmico-oleiras de Iranduba estão dentro da Região Metropolitana de Manaus, mas fora da área da Zona Franca de Manaus e por isso não são beneficiadas com os incentivos fiscais.

O município de Iranduba é conhecido como o principal produtor de artigos cerâmicos, com destaque para o tijolo de 8 furos. Os tijolos, telhas e blocos cerâmicos produzidos em Iranduba são trazidos para a venda na capital do Estado e também são levados para os municípios mais próximos. É pertinente salientar que, o município de Iranduba localiza-se nas proximidades da cidade de Manaus, capital do Amazonas, separando-se apenas pela Ponte Rio Negro.

O acesso ao município pode ser feito tanto de carro, por meio da Ponte, como também de barco, lancha e voadeira comerciais e particulares pelas águas do Rio Negro. Atualmente, os produtos da indústria cerâmico-oleira chegam a Manaus por via terrestre, embarcados em caminhões. Os caminhões são responsáveis pela distribuição dos produtos nas lojas de material de construção em Manaus e adjacências.

A Ponte sobre o Rio Negro foi inaugurada no dia 24 de outubro de 2011, dia em que a cidade de Manaus completou 342 anos. É a primeira ponte estaiada (suspensa por cabos de aço) construída sobre um rio na Amazônia, possui 3.595 metros e custou $\mathrm{R} \$ 1.099,00$ bilhão de Reais. A Ponte chamou e ainda chama bastante atenção e levanta muitas polêmicas, sobretudo, pela grandiosidade do projeto arquitetônico e pelo seu custo final que foi considerado exorbitante. $\mathrm{O}$ fato é que para o setor cerâmico-oleiro a Ponte trouxe maior celeridade para o escoamento da produção. A ponte aproximou as indústrias cerâmico-oleiras do grande mercado consumidor da capital.

A inauguração da Ponte modificou bastante a dinâmica de transporte dos produtos da indústria cerâmico-oleira, bem como das demais mercadorias produzidas nos municípios beneficiados diretamente: Iranduba, Manacapuru e Novo Airão. Antes da existência da Ponte Rio Negro, os produtos (tijolos, frutas, verduras, pescado, iogurte, etc) provenientes destes municípios eram trazidos por meio de barco ou das balsas que realizavam a travessia do Rio Negro até a cidade de Manaus. A travessia demorava uma média de 30 a 40 minutos, dependendo da capacidade do motor da embarcação.

De acordo com Pinheiro (2006), a travessia por meio das balsas constituiu parte importante da história destes municípios, e especialmente, do distrito Cacau Pirêra, local onde se situa o principal porto do município de Iranduba. As primeiras ocupações do Cacau Pirêra datam o ano de 1946, quando o Governo Federal deu suporte para criação de uma Colônia Agrícola. Naquela época, não 


\section{Entre a racionalidade produtiva e a conservação do ambiente: a produção oleira do município de Iranduba e suas consequências ambientais}

havia balsa e a travessia só era feita de barco uma vez por semana com o objetivo de levar a produção dos colonos para vender na cidade.

As balsas começaram a fazer a travessia do Rio Negro em 1974, funcionado assim por 37 anos consecutivos até a inauguração da Ponte Rio Negro. Desde outubro de 2011, tijolos, telhas e demais produtos chegam à cidade de Manaus por meio da ponte, uma vez que as balsas pararam de fazer a travessia no dia da inauguração da ponte. Além disso, o meio terrestre é considerado o mais rápido para realização do transporte (PINHEIRO, 2006).

As indústrias cerâmico-oleiras se encontram instaladas em Iranduba pela abundância de material argiloso no solo. Até a década de 1970, o setor oleiro tinha sua concentração na cidade de Manaus, mas com a explosão urbana, decorrente do processo de implantação da Zona Franca de Manaus iniciado em 1967, muitas indústrias migraram para o município de Iranduba. A opção pelo município foi pelo fato dos terrenos apresentarem jazidas de argila de boa qualidade e em grande quantidade para a fabricação de artefatos cerâmicos, além de localizar-se próximo ao centro urbano de Manaus e possuir oferta de mão de obra a custos mais baixo (GOVERNO DO AMAZONAS, 2012).

De acordo com o Relatório de Impactos Ambientais da travessia do Rio Negro por Ponte (2007), no Iranduba predominam os solos aluvionais arenoargilosos, parcialmente alagadiços. Os solos são agrupados em três tipo: a) solos bem drenados de terra firme de textura média e muito argilosa; b) solos que contém terra firme de textura arenosa e c) solos sujeitos ao excesso de água. Em relação aos ecossistemas, Bueno, Lima e Azevedo (2000) assinalam que o município de Iranduba é formado por dois tipos distintos: a várzea e a terra firme. A terra firme do município se caracteriza pela baixa fertilidade natural, solos fortemente ácidos, com drenagem imperfeita e muito argilosos, condições estas que dificultam o uso agrícola intensivo. Já as áreas de várzea possuem uma fertilidade bem maior em função da renovação dos nutrientes que recebem anualmente pela subida e descida das águas do rio.

Conforme D'Antona et al. (2007), o município de Iranduba possui não só abundâncias, mas variedade de argila, o que permite a mistura entre as mesmas com intuito de produzir um material de qualidade superior. No que diz respeito à exploração da argila, é necessário esclarecer que, bem antes da Constituição Federal de 1988, o Decreto Lei no. 227 de 28/02/1967, conhecido como código de mineração, classificou a argila como mineral de classe II e estabeleceu uma série de procedimentos necessários para a realização de sua exploração, que inclui pesquisa a prévia do solo e o licenciamento. Em relação à classificação, é pertinente destacar que a classe II diz respeito às jazidas de substâncias minerais de emprego imediato na construção civil.

O código de mineração em seu artigo primeiro considera que é competência da União administrar os recursos minerais, a indústria de produção 
Hamida Assunção Pinheiro

Antonio Carlos Witkoski

mineral e a distribuição, o comércio e o consumo de produtos minerais. Nesse caso, a produção das olarias, por relacionar-se como a atividade de mineração, deve adequar-se às preconizações do referido código.

A extração de minério é denominada de lavra, que por sua vez, conforme o art. 36 do código de Mineração, é o "conjunto de operações coordenadas objetivando o aproveitamento industrial da jazida, desde a extração das substâncias minerais úteis que contiver, até o beneficiamento das mesmas". Para a concessão da exploração das jazidas, é necessário que a área já tenha sido pesquisada e que tenha tido o relatório de pesquisa aprovado pelo Departamento Nacional de Produção Mineral - DNPM.

É importante frisar que o tamanho da área a ser explorada será decidido pelo DNPM, de acordo com as condições técnicas e econômicas da localidade onde se situa a jazida e do interessado em explorá-la. O código de mineração não estabelece restrições quanto ao número de concessões feitas para a mesma empresa. Desse modo, no caso das olarias, sempre que haja a diminuição ou o esgotamento da argila adequada para a fabricação dos material cerâmicos, o proprietário poderá solicitar a autorização de outra área.

A solicitação é dirigida pelo interessado ao Ministro das Minas e Energia e deve ser circunstanciada de informações que esclareçam o objetivo da exploração, a disponibilidade de recursos para a extração e para o beneficiamento do minério, bem como, a descrição detalhada e o mapeamento da área. A solicitação pode ser negada, mesmo que a área pesquisada já tenha tido relatório de pesquisa aprovado pelo DNPM, caso a lavra seja considerada prejudicial ao bem público ou comprometer interesses que superem a utilidade da exploração industrial. Nestes casos, o interessado terá direito a ser ressarcido no que se refere às despesas realizadas para o trabalho de pesquisa.

Quando a lavra é concedida, o código estabelece que, além da autorização fornecida pelo diretor geral do DNPM, seja publicada no Diário Oficial da União uma portaria assinada pelo Ministro das Minas e Energia, a qual é imprescindível para que o interessado requeira a posse da jazida. Além disso, o interessado deve realizar a extração em conformidade com o detalhamento apresentado durante a solicitação, sob pena de ser advertido, multado ou até mesmo perder a concessão. Para o controle da lavra pelo órgão ambiental, o interessado fica obrigado a apresentar relatório anual de todas as atividades desenvolvidas.

A Lei no. 9.314 de 14/11/1996 alterou alguns dispositivos do código de mineração. Vale mencionar que esta prevê que o concessionário da lavra tem direito de solicitar a suspensão temporária das atividades, bem com renunciar ao direito de concessão a qualquer tempo, desde que apresente justificativa plausível, por escrito, ao ministro das Minas e Energia, mais propriamente ao diretor do DNPM. Não sendo aceitas as justificativas, o ministro ou diretor do DNPM pode exigir a continuação dos trabalhos e ainda aplicar multa se houver irregularidades.

Latitude, vol. 5, n², pp.49-73, 2011. 


\section{Entre a racionalidade produtiva e a conservação do ambiente: a produção oleira do município de Iranduba e suas consequências ambientais}

Esta lei define ainda parâmetro quantitativos para a aplicação de multa. Em seu art. 64, está previsto que a multa inicial variará de 100 (cem) a 1.000 (um mil) UFIR, segundo a gravidade das infrações e, em caso de reincidência, a multa será cobrada em dobro.

Como alternativa para a mitigação dos impactos ambientais, a legislação possui um instrumento denominado de Plano de Recuperação de Áreas Degradadas - PRAD. Este instrumento, utilizado para a transformação de áreas degradadas em áreas não degradadas, tem como objetivo o restabelecimento da capacidade produtiva e/ou a melhoria da qualidade ambiental da área, o que nem sempre quer dizer que a área voltará a sua condição original. No caso das cavas para a retirada de argila, não há como recuperar a área de modo original, entretanto existem outras de recuperação ou reaproveitamento do terreno.

O PRAD foi regulamentado pelo Decreto 97.632 de 10/04/1989, o qual definiu que, para empreendimentos de exploração dos recursos minerais, deverá ser apresentado o PRAD, além do EIA e do RIMA. É importante destacar que a obrigatoriedade da recuperação de áreas degradas já estava presente na Política Nacional de Meio Ambiente - PNMA (1981), bem como na Constituição Federal de 1988. Todavia, por tratar-se de um instrumento de difícil monitoramento, recentemente, o Instituto Brasileiro do Meio Ambiente e dos Recursos Naturais Renováveis-IBAMA divulgou a Instrução Normativa no. 04 de 13/04/2011. Conforme a referida IN, o PRAD deve reunir informações, diagnósticos, levantamentos e estudos que permitam a avaliação da degradação ou alteração e a consequente definição de medidas técnicas adequadas à recuperação da área. Assim, o PRAD se apresenta como uma possibilidade de fomentar a sustentabilidade dos recursos naturais, de modo a prevenir o escassez dos recursos.

Além da autorização da União para o direito de explorar, as olarias e demais atividades industriais que realizam mineração também necessitam da licença ambiental, a qual é concedida no Estado do Amazonas pelo Instituto de Proteção Ambiental do Amazonas - IPAAM. O processo de licenciamento ambiental se desenvolve em várias etapas que são norteadas pelas Resoluções do Conselho Nacional de Meio Ambiente - CONAMA no. 01 de 23/01/1986, no. 10 de 06/12/1990 e no. 237 de 19/12/1997.

A primeira resolução supracitada estabelece a necessidade de desenvolvimento de Estudo de Impacto Ambiental-EIA e de elaboração do Relatório de Impacto Ambiental-RIMA, bem como sua aprovação pelo órgão ambiental competente para as atividades de extração de minério, inclusive os de classe II. Este instrumento, ao exigir o EIA e o RIMA, restringe a realização de ações aleatórias que propiciem a degradação dos recursos naturais.

A resolução no. 10 do CONAMA dispõe sobre as normas específicas para o licenciamento ambiental para extração de mineral classe II, estabelecendo a 
Hamida Assunção Pinheiro

Antonio Carlos Witkoski

necessidade de ser requerida pelo interessado na exploração do recurso a Licença Prévia-LP, posteriormente, a Licença de Instalação-LI e, por fim, a Licença de Operação-LO. A LP é requeria pelo interessado junto ao órgão ambiental competente, para isso é necessário que o mesmo apresente o EIA e o RIMA para apreciação. Já para a obtenção LI, que também deverá ser pedida ao órgão ambiental competente, é preciso que o interessado apresente o Plano de Controle Ambiental - PCA, o qual deverá oferecer de forma clara e objetiva um conjunto de procedimentos que minimizem os impactos ambientais decorrentes da exploração do recurso. A última fase é a aquisição da $L O$, a qual só pode ser requerida por quem já conseguiu a LP e a LI. Neste último momento do processo de licenciamento ambiental, a solicitação é feita ao DNPM.

A resolução no. 237 reitera a necessidade da LP, da LI e da LO e estabelece parâmetros temporais para cada uma delas. A LP não pode ultrapassar o período de 5 anos, a LI não pode ser superior a 6 anos e a LO deve durar no mínimo 4 e no máximo 10 anos. Além disso, no anexo I da referida lei, estão relacionadas as atividades que estão sujeitas ao licenciamento ambiental, destacando-se aí a extração e tratamento de minério.

A indústria oleira se destaca na economia do Iranduba pela sua rentabilidade, mas nem por isso, pode-se deixar de perceber os danos ambientais decorrentes deste ramo de produção. Os danos ambientais marcam a paisagem do município: as escavações, a poeira, a fumaça, os gases poluentes, os cascalhos de cerâmica, o barulho das máquinas. Estes são alguns exemplos de danos ambientais que podem ser facilmente observados em uma rápida visita ao município.

A paisagem do município é marcada por uma grande quantidade de escavações (figura 1) realizadas com a finalidade de retirada de argila. Em áreas públicas ou privadas as retroescavadeiras realizam explotação de material para as indústrias, produzindo muita poeira e deixando cavas a céu aberto. Os buracos que ficam após a retirada da argila enchem de água das chuvas e acumulam sujeiras diversas: garrafas pets, pneus, sacolas plásticas entre outras.

Latitude, vol. 5, n², pp.49-73, 2011. 


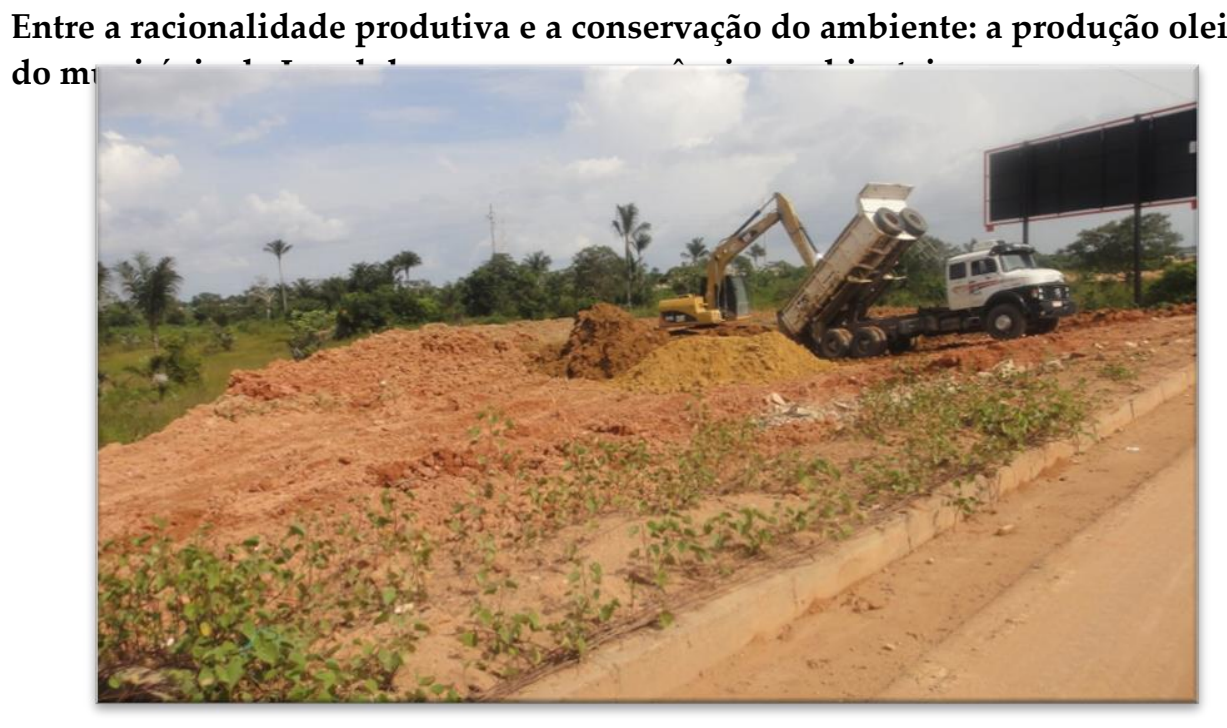

Figura 1- Escavação para retirada de argila.

FONTE - Foto dos autores-Pesquisa de campo, 2012

É relevante registar que a argileira ou barreira, como também é chamada, é o terreno ou uma parte do terreno de onde se retira a argila. A área pode ser localizada próximo ou distante da indústria cerâmico-oleira. No município de Iranduba, é comum que cada indústria cerâmico-oleira tenha sua própria argileira, não foi identificada até o momento nenhuma indústria no município que realize apenas a explotação e beneficiamento da argila, o que já existe em outras regiões do país.

Outra particularidade que merece destaque é que as argileiras em geral são exploradas, principalmente, no período de agosto a novembro, uma vez que grande parte do município de Iranduba é composta por terra de várzea, ou seja, áreas que permanece alagadas durante boa parte da enchente ${ }^{2}$ e da cheia. Para ser

2 Cf. Witkoski (2006), em Terra, floresta e água, apresenta um calendário dos ciclos sazonais dos rios amazônicos, considerando quatro períodos distintos durante o ano: enchente (dezembro a abril), cheia (maio a julho), vazante (agosto e setembro), seca (outubro e novembro). É claro que os fenômenos climáticos podem apresentar variações de um ano para o outro e sofrer interferências de outros fenômenos naturais, causando atraso ou adiantamento nos ciclos dos rios. 
Hamida Assunção Pinheiro

Antonio Carlos Witkoski

explorada, a argileira não pode estar encharcada de água, é necessário que a argila esteja seca.

Após a explotação, a argila é estocada na indústria (figura 2), a reserva é feita para os meses em que não se pode fazer a extração. Desse modo, as olarias necessitam fazer um planejamento para a produção e precisam ainda ter espaço para guardar a argila. Em algumas olarias há galpões cobertos e protegidos para armazenar a argila, como é o caso mostrado na figura 2, mas outras empresas menores, a argila fica apenas coberta por lona ou até mesmo exposta às intempéries, o que facilita o desperdício de material e contribui para a exploração desnecessária dos recursos naturais.

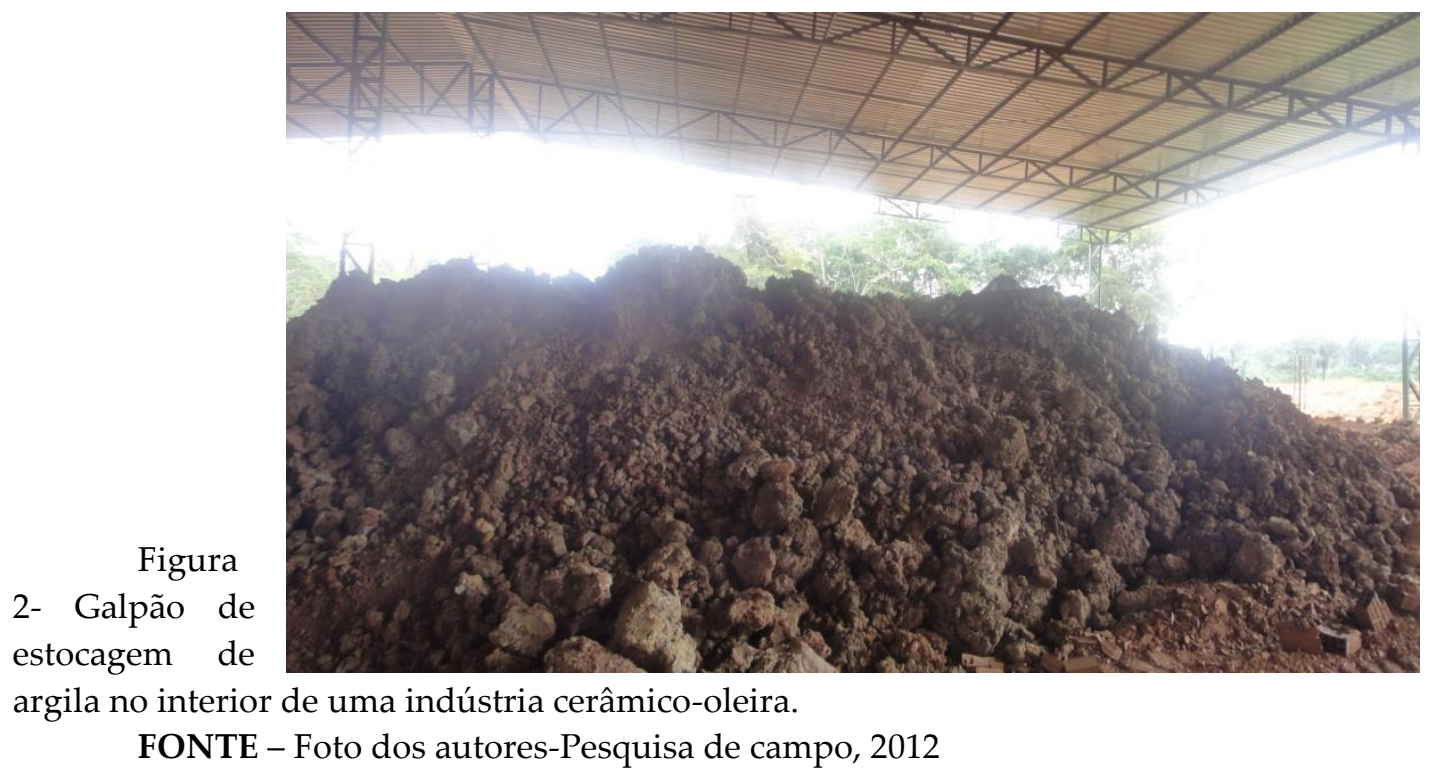

A extração ilegal de argila produz um dano ambiental gravíssimo e tem sido uma constante em Iranduba. Frequentemente o órgão ambiental faz fiscalização e descobre argileiras clandestinas, sobretudo em áreas proibidas por serem Áreas de Preservação Permanente - APP, como são as margens e os leitos dos rios e igarapés (figura 3). A argila das margens dos cursos d'água é muito apreciada pelos oleiros devido sua capacidade de plasticidade e resistência, o que provoca uma ação predatória nas margens dos rios e igarapés. As olarias nem sempre solicitam o licenciamento da jazida e alegam uma diversidade de motivos: falta de conhecimento da legislação, carência financeira para pagar as taxas cobradas pelo órgão ambiental, morosidade no processo de licenciamento, entre outros. Existem casos em que o dono da olaria solicita a autorização para a 


\section{Entre a racionalidade produtiva e a conservação do ambiente: a produção oleira do município de Iranduba e suas consequências ambientais}

explotação da argila, a mesma é concedida e, mesmo assim, ele explora em outro lugar de forma clandestina, alegando que a argila tem mais qualidade do que aquela da jazida licenciada.

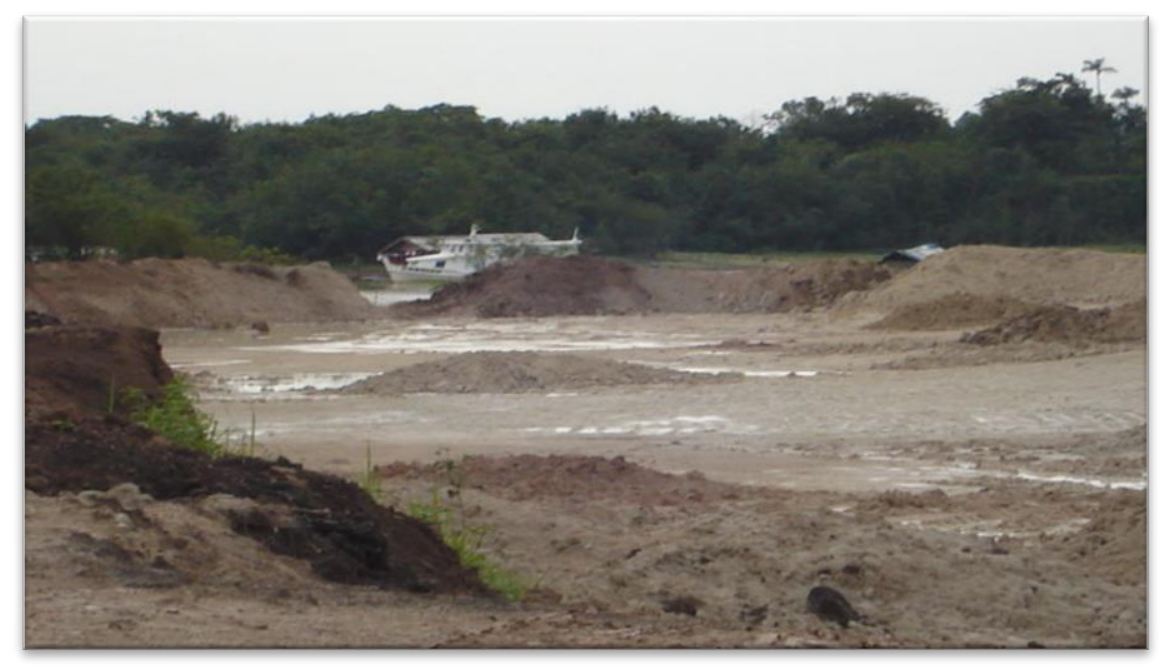

Figura 3- Exploração de argila na margem do Rio Negro.

FONTE - Foto dos autores-Pesquisa de campo, 2012

A retirada de argila das margens dos cursos d'água tem trazido muitas consequências negativas ao ambiente, que por sua vez, prejudicam as condições de vida dos moradores do município. Em épocas de seca é comum observar máquinas do tipo retroescavadeira hidráulica operando nas margens e até mesmo no leito dos Rio Negro para retirada de argila.

Com a perda da mata ciliar, os rios e igarapés ficam mais vulneráveis e, na época da cheia, suas águas escapam, ocasionando grandes alagações. No ano de 2012, o Amazonas registrou a pior enchente histórica pelo nível de elevação das águas. O Rio Negro superou a cota de 2009, que era de 29,77 metros acima do nível do mar, chegando a 29,97 metros. Em Iranduba, a enchente atingiu vários bairros deixando casas, comércios e inclusive olarias submersas. A figura 4 mostra uma rua do município que precisou receber uma elevação de madeira em forma de ponte para se tornar acessível aos pedestres. Estas alagações são também responsáveis pelo aparecimento de doenças que afetam a saúde dos moradores e ainda pelo aparecimento de animais perigosos como as cobras. Além disso, têm os transtornos para a vidas dos moradores que precisam sair de suas residências ou elevar os assoalhos para permanecer no local. 
Hamida Assunção Pinheiro

Antonio Carlos Witkoski

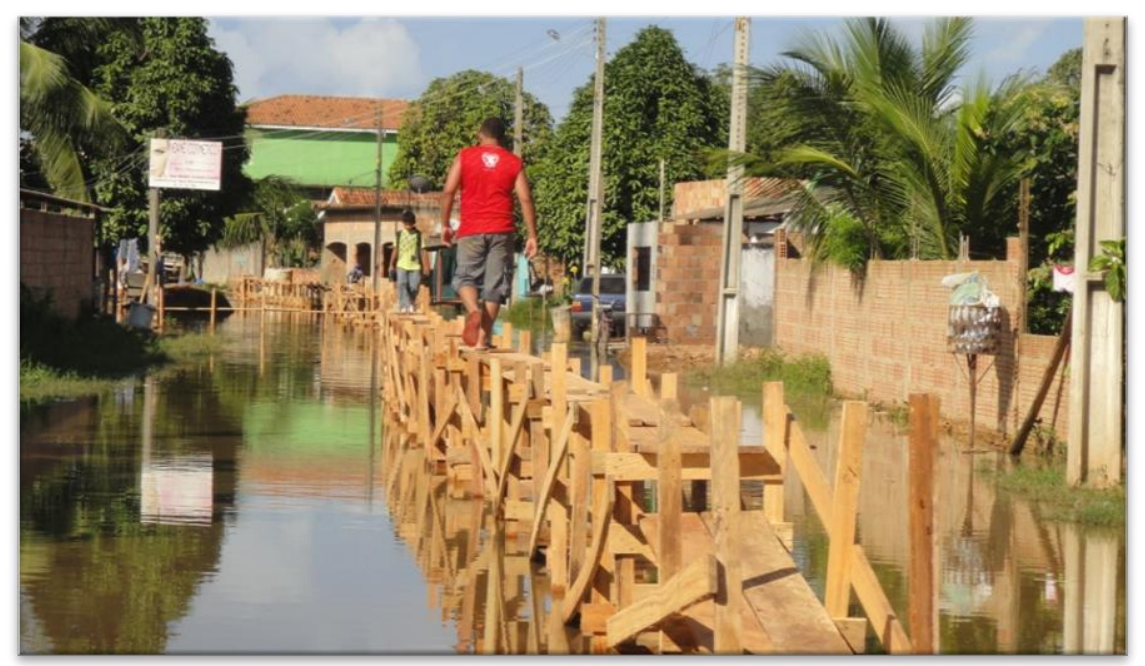

Figura 4- Ponte de madeira construída sobre a rua alagada na cheia de 2012.

FONTE - Foto dos autores-Pesquisa de campo, 2012

Outro dano ambiental que pode ser facilmente observado por todos que moram ou que passam pelo município é a fumaça escura (figura 5) lançada pelas chaminés dos fornos durante o processo de queima ou cozimento dos produtos cerâmicos. Em geral, as olarias possuem várias chaminés, que permanecem queimando os artefatos cerâmicos de forma contínua por até 72 horas. Como o processo não pode ser interrompido a fumaça permanece dia e noite. A fumaça expelida causa poluição do ar e prejudica até mesmo a saúde dos trabalhadores, dos moradores e dos transeuntes que circulam nas proximidades das indústrias, causando irritação na garganta, nos olhos e na pele.

Latitude, vol. 5, n², pp.49-73, 2011. 
Entre a racionalidade produtiva e a conservação do ambiente: a produção oleira do município de Iranduba e suas consequências ambientais

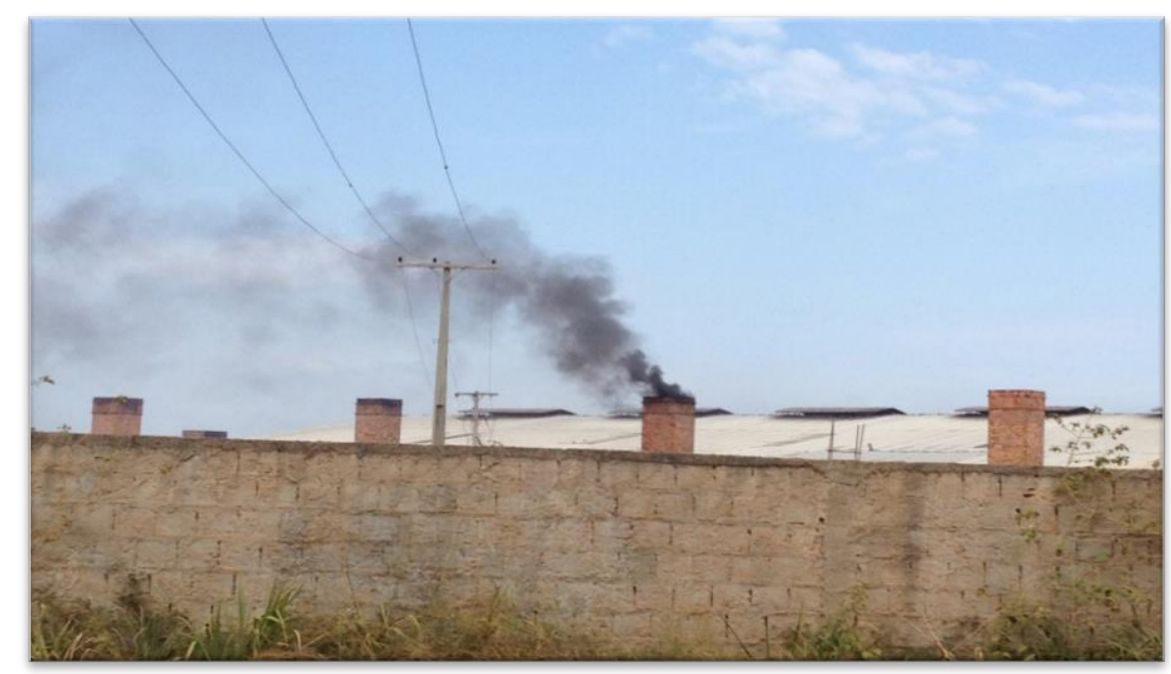

Figura 5- Emissão de fumaça escura pelas chaminés dos fornos de uma indústria.

FONTE - Foto dos autores-Pesquisa de campo, 2012

A legislação prevê que as indústrias que emitem gases poluentes instalem filtros nas chaminés para evitar ou mesmo amenizar a poluição, no entanto muitas empresas descumprem a normativa alegando que o equipamento é de custo muito elevado. Grande parte das indústrias cerâmico-oleiras em Iranduba ainda empregam a lenha como principal fonte para a combustão nos fornos, apesar do gasoduto Coari-Manaus, que transporta gás natural, ter passado pelo município, não houve até o momento, qualquer incentivo para modificação do processo de queima.

O uso da lenha nos fornos (figura 6) tem gerado o desflorestamento de grandes áreas. Em muitos casos, a derrubada de árvores para fazer lenha é feita de 
Hamida Assunção Pinheiro Antonio Carlos Witkoski

forma ilegal e não obedece minimamente a qualquer plano de manejo ou reflorestamento, o que também provoca danos consideráveis ao ambiente. A legislação prevê que a madeira usada nos fornos seja certificada, ou seja, tenha o Documento de Origem Florestal - DOF, no entanto muitas fiscalizações realizadas pelo órgão ambiental se deparam com madeira de origem não especificada.

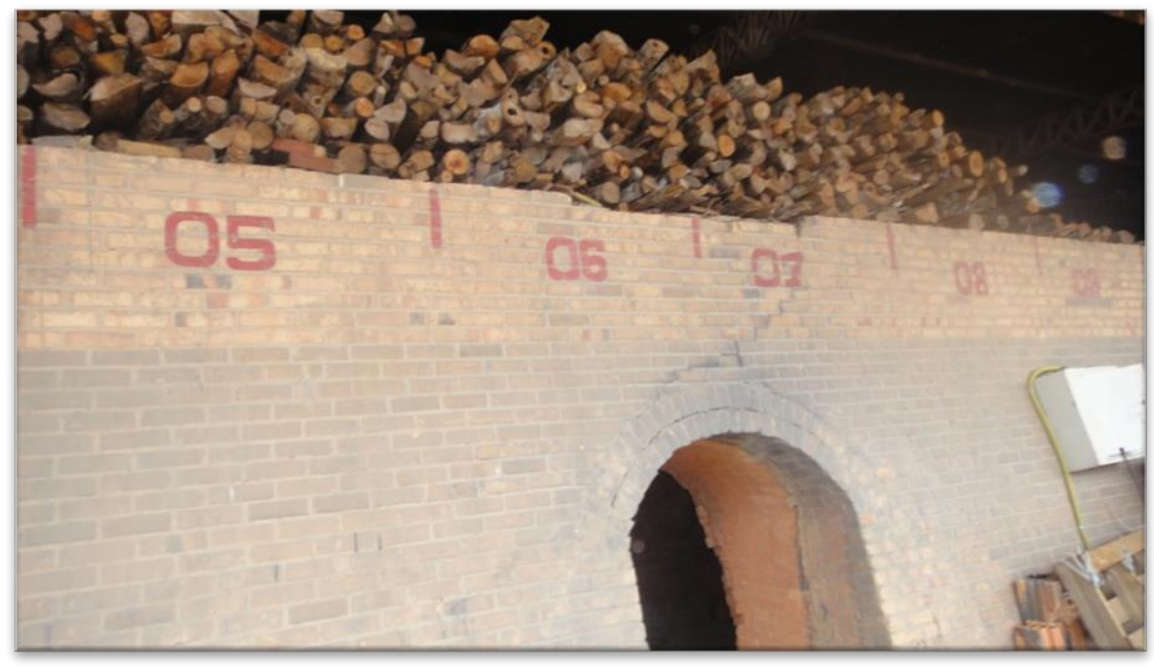

Figura 6- Estoque de lenha para abastecer forno

FONTE - Foto dos autores/Pesquisa de campo, 2012

Os cascalhos ou restos de materiais cerâmicos (Figura 7) despejados indevidamente em várias esquinas e/ou terrenos baldios no município é outro dano ambiental recorrente. Esta prática além de deixar a localidade com aspecto feio, sujo e desorganizado, contribui para o acúmulo de outros resíduos sólidos trazidos pela população em geral, como é o caso do lixo doméstico. Isto ocasiona a presença de alguns lixões a céu aberto em várias partes do município, propiciando 


\section{Entre a racionalidade produtiva e a conservação do ambiente: a produção oleira do município de Iranduba e suas consequências ambientais}

a proliferação de ratos e outros insetos que prejudicam à saúde da população. Além desse aspecto, os cascalhos ou restos de materiais cerâmicos jogados nas proximidades das ruas provocam acidentes de trânsito e de pedestres, pneus furados, pés cortados, etc.

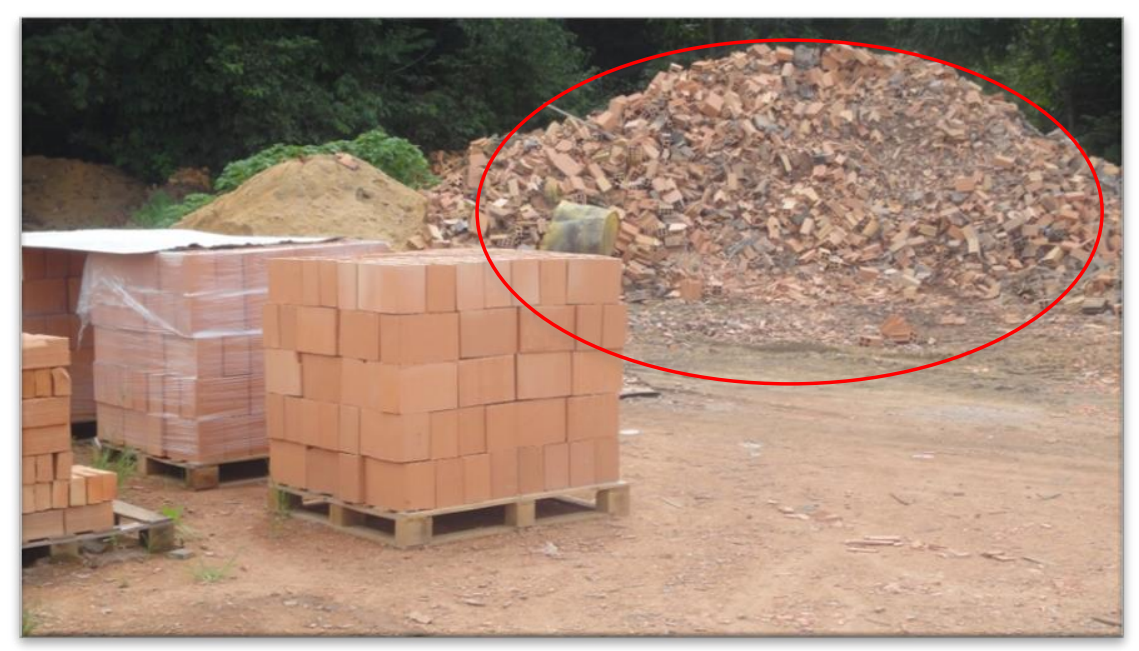

Figura 7- Restos de produção

FONTE - Foto dos autores/Pesquisa de campo, 2012

Como se vê, os danos ambientais são diversificados. Muitas indústrias cerâmico-oleiras em Iranduba praticam ações insustentáveis à conservação do ambiente há décadas. Em alguns casos, já foram notificadas e multadas pelo órgão ambiental e mesmo assim permanecem na ilegalidade cometendo infrações. Há empresas que continuam funcionando mesmo sem ter as licenças.

A fiscalização realizada pelo órgão ambiental é importante e traz bons resultados, entretanto, trata-se de processos de difícil monitoramento. As áreas de exploração de argila e de desflorestamento, por exemplo, situam-se mata adentro e, às vezes, só são localizadas com uso de Global Position System - GPS. Muitas argileiras clandestinas são preparadas para não serem vistas pelos que passam, são colocados troncos e galhos de árvore para impedir o acesso de pessoas não autorizadas.

Por outro lado, o órgão ambiental tem inúmeras dificuldades para realizar o monitoramento: insuficiência de recursos humanos especializados, carência de recursos humanos efetivos, falta de materiais e equipamentos, dificuldade de logística etc. Além disso, há a grande demanda de serviço, uma vez que o órgão 
Hamida Assunção Pinheiro

Antonio Carlos Witkoski

ambiental precisa acompanhar todos os ramos produtivos que afetam o meio ambiente.

Não se pode deixar de reconhecer que algumas indústrias veem inserindo tecnologia mais limpas na fabricação dos produtos e, pouco a pouco, algumas atividades estão se modificando. Como exemplo, tem-se em a substituição da lenha pelo pó de serragem ou restos de construção civil para a queima, a construção de galpões para armazenagem mais eficiente da argila, o uso de paletes de madeira para a embalagem de modo a evitar a quebra excessiva e diminuir a quantidade de cascalhos e o reaproveitamento da águas da chuvas para o umedecer a argila quando a mesma entra na maromba de produção

Há ainda outras formas de inserção tecnológica no mundo cerâmico-oleiro, as quais veem ditando mudanças no processo produtivo e no perfil dos trabalhadores. Máquinas começam a substituir o trabalho humano ou requisitar menor quantidade de trabalhadores, o que produz desemprego e relações de trabalho instáveis.

A introdução de tecnologias vem proporcionando a melhoria de algumas atividades, tornando o trabalho menos exaustivo, bem como também vem possibilitando aumento de produtividade para a indústria cerâmico-oleira. Observa-se, obviamente, um empenho muito maior dos empresários ceramistas para por em prática inovações que tem como resultado direto a diminuição da despesas financeiras com a produção, o que não ocorre quando se trata de inovações que possibilitam diminuir os impactos negativos ao ambiente.

Maciel (2010) estudou a natureza das inovações tecnológicas no Polo cerâmico-oleiro de Iranduba (AM) e, evidenciou que, este processo ainda é bastante recente e pontual, tendo iniciado em 2005 apenas em duas empresas. $\mathrm{O}$ processos de inovações tecnológicas apesar de se reverterem em possível aumento do lucro, exigem investimento financeiro que nem sempre esta ao alcance do proprietário.

Por fim, é preciso entender estes processos à luz dos conceitos de racionalidade econômica ou produtiva discutidos na primeira parte desde artigo. As indústrias cerâmico-oleiras de Iranduba estão inseridas em um ambiente de competição e, por isso, buscam produzir mais, gastar pouco e vender muito. Esta á a receita para se manter no mercado capitalista.

\section{CONCLUSÃO}

$\mathrm{Na}$ atualidade, a crise ecológica vem evidenciando a necessidade de proteção e de conservação dos recursos naturais. No caso da argila, há uma legislação ambiental, que se cumprida for, pode assegurar um uso mais sustentável. É importante considerar que a base produtiva das olarias é um recurso natural não renovável, ou seja, que cedo ou tarde entrará em processo de exaustão.

Latitude, vol. 5, n², pp.49-73, 2011. 
Entre a racionalidade produtiva e a conservação do ambiente: a produção oleira do município de Iranduba e suas consequências ambientais

Justamente por isso, é imprescindível não só o uso racional da argila, mas também o desenvolvimento de formas produtivas diversificadas para que no futuro a localidade não dependa tanto apenas da atividade oleira.

A degradação do meio ambiente é uma consequência da compulsão pela produção e pelo consumo da economia capitalista. A avidez por lucro traz graves consequências ambientais, as quais comprometem até mesmo o futuro da humanidade. Pensar a sustentabilidade deve ser entendido como um compromisso de todos, a reflexão é apenas o primeiro passo, visto que para chegarmos às melhorias é necessários ações transformadoras.

A perspectiva defendida pela racionalidade ambiental pode trazer grandes contribuições para os processos produtivos dos mais diversos ramos. No caso da indústria cerâmica-oleira, mesmo que não seja possível solucionar todos os problemas ambientais já causados, é possível minimizá-los e aplicar inovações tecnológicas que evitem a continuidade dos danos daqui para frente. 
Hamida Assunção Pinheiro

Antonio Carlos Witkoski

\section{REFERÊNCIAS}

ABREU, Nádia Rafaela Pereira; SILVA, Deiziane Marreiro; CARVALHO, Daniela Paiva; SAMPAIO, Francisca Pauliane Riberio. Uma abordagem geográfica dos aspectos físicos e dos potenciais econômicos do solo de Iranduba - AM. Revista Geonorte. Manaus. Edição Especial, V.2, N4, 2012. Disponível em: http://www.revistageonorte.ufam.edu.br/attachments/009_UMA\%20ABORDAGE M\%20GEOGRÁFICA\%20DOS\%20ASPECTOS\%20FÍSICOS\%20E\%20DOS\%20POT ENCIAIS\%20ECONÔMICOS\%20DO\%20SOLO\%20DE\%20IRANDUBA\%20\%20AM.pdf. Acessado em 26/12/2012.

ACERAM, Associação dos ceramistas do Estado do Amazonas. Lista dos associados. Iranduba, 2012.

BRASIL. Constituição da República Federativa do Brasil. Promulgada em 05/05/1988. São Paulo: Saraiva, 2003.

Decreto-lei no. 227 de 28/02/1967. Institui o Código de Mineração. Disponível em: http://www.planalto.gov.br/ccivil_03/decreto-lei/Del0227.htm. Acessado em 04 de setembro de 2011.

.Lei no. 6.938 de 31/08/1981. Dispõe sobre a Política Nacional do Meio Ambiente, seus fins e mecanismos de formulação e aplicação, e dá outras providências. Disponível em http://www.planalto.gov.br/ccivil_03/leis/L6938.htm. Acessado em 04 de setembro de 2011.

.Lei no. 9.314 de 14/11/1996. Altera dispositivos do Decreto-lei no 227, de 28 de fevereiro de 1967, e dá outras providências. Disponível em: http://www.planalto.gov.br/ccivil_03/Leis/L9314.htm. Acessado em 04 de setembro de 2011.

BUENO, Newton; LIMA, Roberval Monteiro B. de; AZEVEDO, Celso Paulo de. Contribuições de espécies florestais para fins energéticos sobre algumas características químicas de um podzólico amarelo impactado por usos anteriores no município de Iranduba - AM. Instruções técnicas no. 11. Manaus: EMBRAPA;

Latitude, vol. 5, n², pp.49-73, 2011. 
Entre a racionalidade produtiva e a conservação do ambiente: a produção oleira do município de Iranduba e suas consequências ambientais

Ministério da agricultura e do abastecimento, 2000. Disponível em: http: //www.infoteca.cnptia.embrapa.br/bitstream/doc/670826/1/IT112000.pdf. Acessado em 17/07/2012.

CESAR, Monica de Jesus. "Empresa-cidadã: uma estratégia de hegemonia. São Paulo: Cortez, 2008.

CHAVES, Maria do Céu Câmara. Iranduba: ribeirinhos na travessia produzida análise de um projeto de Estado para populações rurais no Estado do Amazonas. Dissertação (mestrado)-Fundação Getúlio Vargas. Rio de Janeiro, 1990.

CONAMA. Conselho Nacional de Meio Ambiente. Resolução no. 01 de 23/01/1986. Disponível em http://www.mma.gov.br/port/conama/legiano.cfm?codlegitipo=3. Acessado em 23 de setembro de 2011.

CONAMA. Conselho Nacional de Meio Ambiente. Resolução no. 10 de 06/12/1990. Disponível em http://www.mma.gov.br/port/conama/legiano.cfm?codlegitipo=3. Acessado em 23 de setembro de 2011.

CONAMA. Conselho Nacional de Meio Ambiente. Resolução 237 de 19/12/1997. Disponível em http://www.mma.gov.br/port/conama/legiano.cfm?codlegitipo=3. Acessado em 23 de setembro de 2011.

D'ANTONA. Raimundo de Jesus Gato; REIS, Nelson Joaquim; MAIA, Maria Adelaide Mancine; ROSA, Sebastião Ferreira; NAVA, Daniel Borges. Projeto Materiais de Construção na área Manacapuru -Iranduba- Manaus - Careiro (Domínio baixo Solimões). Série Rochas e minerais industriais. Manaus: CPRM - Serviço Geológico do Brasil, 2007.

GOVERNO DO AMAZONAS. Plano de Desenvolvimento Preliminar de Arranjos Produtivos Locais de Base Mineral Cerâmico-oleiro - Cidade Polo: Iranduba. Manaus, $2009 . \quad$ Disponível em: http: \|www.desenvolvimento.gov.br/arquivos/dwnl_1248263306.pdf. Acessado em 18/07/2012. 
Hamida Assunção Pinheiro

Antonio Carlos Witkoski

IBAMA. Instituto Brasileiro do Meio Ambiente e dos Recursos Naturais Renováveis. Instrução Normativa No. 04 de 13/04/2011. Disponível em http://www.ibama.gov.br/. Acessado em 04 de setembro de 2011.

LEFF, Enrique. Racionalidade ambiental: a reapropriação social da natureza. Tradução de Luís Carlos Cabral. Rio de Janeiro: Civilização brasileira, 2006.

Saber Ambiental: sustentabilidade, racionalidade, complexidade, poder. Tradução de Lúcia Mathilde Endlich Orth. 6ª Ed. Petrópolis, RJ: Vozes, 2008.

.A cultura como mediação entre os processos econômicos e os processos ecológicos. In: LEFF, E. Ecologia, capital e cultura: a territorialização da racionalidade ambiental. Tradução de Jorge E. Silva. Petrópolis, RJ: Vozes, 2009.

LIMA-e-SILVA, P. P., GUERRA, J. T. e MOUSINHO, P. (org.). Dicionário brasileiro de ciências ambientais. Rio: Thex Editora, 1999.

MACIEL, Cleiton Ferreira. A natureza das inovações tecnológicas no Polo-Cerâmico de Iranduba (AM). (monografia) Departamento de Ciências Sociais da Universidade Federal do Amazonas, 2010.

PINHEIRO, Hamida Assunção. Fronteiras da Vida: o tradicional e o moderno no Cacau Pirêra/ Iranduba (AM). (Dissertação) Programa de Pós-Graduação em Sociedade e Cultura na Amazônia da Universidade Federal do Amazonas, 2006.

UNIVERSIDADE FEDERAL DO AMAZONAS. Centro de Ciências do Ambiente. Relatório de Impactos Ambientais do empreendimento de travessia do Rio Negro por ponte. Manaus: Outubro, 2007.

Latitude, vol. 5, n², pp.49-73, 2011. 
Entre a racionalidade produtiva e a conservação do ambiente: a produção oleira do município de Iranduba e suas consequências ambientais

WITKOSKI, Antonio Carlos. Terra, floresta e água: os camponeses amazônicos e as formas de uso de seus recursos naturais. Manaus: Edua, 2006. (Série: Amazônia: A terra e o homem). 
Latitude, vol. 5, n`2, pp.49-73, 2011

DOI: https://doi.org/10.28998/2179-5428.20110204 